\title{
Studies on Histones
}

\section{THE HISTONES OF WHEAT GERM*}

\author{
By E. W. JOHNS AND J. A. V. BUTLER \\ Chester Beatty Research Institute, Institute of Cancer Research: Royal Cancer Hospital, London, S.W. 3
}

(Received 21 February 1962)

Histones from a number of animal tissues have been shown to be divisible into three main types, which are roughly characterized according to the predominant basic residues: $f 1$, lysine-rich; $f 2$, moderately lysine-rich; f 3, arginine-rich (Johns, Phillips, Simson \& Butler, 1960). Preparations of these fractions from several tissues of the calf and rat showed no marked differences between similar fractions from different tissues, either in their compositions or in their starch-gel-electrophoresis patterns (Hnilica, Johns \& Butler, 1962).

To see if this similarity also holds with widely different species, we have examined preparations of the histones from wheat germ. A previous preparation from this source was described by Cruft, Mauritzen \& Stedman (1957b), who examined it by electrophoresis at $\mathrm{pH} 6 \cdot 15$ and found that, although it was heterogeneous, the principal fraction was unlike the $\beta$-fractions from animal tissues. However, no complete analyses were given.

\section{EXPERIMENTAL AND RESULTS}

Preparation of wheat-germ histone. The methods normally used for extracting histone or histone fractions from animal tissues were applied to wheat germ without success. These methods, including hydrochloric acid extractions (Davison, James, Shooter \& Butler, 1954), ethanol-hydrochloric acid extractions (Johns et al. 1960) and perchloric acid extractions (Johns \& Butler, 1962), were applied to the original tissue and to the tissue washed with sodium chloride solution, but in all cases gave proteins that contained a greater proportion of acidic than of basic amino acids. A good histone was finally obtained in reasonable yield by acid extraction of deoxyribonucleoprotein prepared according to Mirsky \& Pollister (1942).

Wheat germ $(500 \mathrm{~g}$.) was suspended in $1200 \mathrm{ml}$. of light petroleum (b.p. $80-100^{\circ}$ ) and heated to $80^{\circ}$ on a water bath for $15 \mathrm{~min}$. The suspension was filtered through a no. 1 sintered-glass filter and the wheat germ extracted again in the same way. All operations after this extraction were carried out at $4^{\circ}$.

* Parts 1, 2 and 3: Johns \& Butler (1962), Hnilica, Johns \& Butler (1962) and Phillips \& Simson (1962) respectively.
The residue from the second extraction was washed six times with acidified sodium chloride solution as described for calf thymus by Phillips \& Johns (1959). The saline-washed residue (approximate volume $700 \mathrm{ml}$.) was then mixed with $500 \mathrm{ml}$. of $0.15 \mathrm{M}$-sodium chloride ( $\mathrm{pH} \mathrm{7.0}$ ) and $1200 \mathrm{ml}$. of 3.5 M-sodium chloride was added slowly with stirring. The stirring was continued for $18 \mathrm{hr}$. to obtain the maximum dissociation possible. The viscous solution resulting from the dissociation of the deoxyribonucleoprotein was centrifuged at $1100 \mathrm{~g}$ (av.) for $3 \mathrm{hr}$. in an International refrigerated centrifuge to remove most of the insoluble material, and finally for $1 \mathrm{hr}$. at $24000 \mathrm{~g}$ (av.) in a model L Spinco ultracentrifuge. The supernatant was then poured into $6 \mathrm{l}$. of cold water and the fibrous deoxyribonucleoprotein that formed was wound on to a glass stirring rod and transferred to a ball mill. The histone was extracted from the deoxyribonucleoprotein as described previously for calf thymus (Davison et al. 1954) and the clarified extract $(700 \mathrm{ml}$.) was dialysed four times for $5 \mathrm{hr}$. against $6 \mathrm{l}$. of $1 \mathrm{mN}$-hydrochloric acid and freezedried. The yield of wheat-germ histone was $1.96 \mathrm{~g}$. The total and $N$-terminal amino acid analyses are given in Table 1, together with those of calfthymus histone for comparison.

Starch-gel electrophoresis. The wheat-germ histone was examined by starch-gel electrophoresis at $\mathrm{pH} 2$ as described for calf-thymus histones by Johns, Phillips, Simson \& Butler (1961). The pattern obtained (Fig. 1) was quite different from that obtained with the whole histones from calf thymus, which is shown for comparison. The two slow bands that correspond to the arginine-rich group in the calf-thymus histone are hardly visible in the wheatgerm histone.

Fractionation of wheat-germ histone. An attempt was made to fractionate the wheat-germ histone by chromatography on carboxymethylcellulose as described previously for calf-thymus histone (Johns et al. 1960). Although three apparently welldefined peaks were obtained, total amino acid analyses showed no significant differences between them.

However, a method that has given two distinct fractions has been developed as described below. 
Table 1. Composition of histone and histone fractions prepared from calf thymus and wheat germ

Amino acids are expressed as moles/100 moles of all amino acids found.* The proportion of $N$-terminal amino acids are molar percentages of all such groups found.

\begin{tabular}{|c|c|c|c|c|c|c|c|}
\hline & Whol & tone & & & & & \\
\hline & & & & & & & \\
\hline Amino acid & thymus & germ & fl & f2 & f3 & (A) & (B) \\
\hline $\left.\begin{array}{l}\text { Aspartic acid } \\
\text { Glutamic acid }\end{array}\right\} \quad$ Acidic & $14 \cdot 2$ & $\begin{array}{l}4 \cdot 4 \\
8 \cdot 6\end{array}$ & $\begin{array}{l}2 \cdot 7 \\
7 \cdot 0\end{array}$ & $14 \cdot 3$ & $\begin{array}{r}4 \cdot 2 \\
12 \cdot 0\end{array}$ & $\begin{array}{l}4 \cdot 8 \\
8 \cdot 6\end{array}$ & $\begin{array}{l}5 \cdot 7 \\
8 \cdot 0\end{array}$ \\
\hline Glycine & $8 \cdot 5$ & $8 \cdot 1$ & $5 \cdot 6$ & $10 \cdot 3$ & $6 \cdot 1$ & $6 \cdot 1$ & $8 \cdot 7$ \\
\hline Alanine & $13 \cdot 8$ & $15 \cdot 5$ & 22.9 & $11 \cdot 1$ & $13 \cdot 7$ & $16 \cdot 1$ & $12 \cdot 9$ \\
\hline Valine & $6 \cdot 4$ & $5 \cdot 5$ & $4 \cdot 3$ & $7 \cdot 5$ & $5 \cdot 7$ & $5 . \overline{9}$ & $6 \cdot 4$ \\
\hline Leucines & $10 \cdot 6$ & $12 \cdot 3$ & $6 \cdot 4$ & $12 \cdot 7$ & $13 \cdot 6$ & $9 \cdot 4$ & $14 \cdot 6$ \\
\hline Phenylalanine & 1.9 & $2 \cdot 2$ & $1 \cdot 3$ & $\mathbf{1} \cdot \mathbf{5}$ & 2.4 & $2 \cdot 6$ & 2.5 \\
\hline Tyrosine & $1 \cdot 7$ & $1 \cdot 7$ & - & $2 \cdot 7$ & $\mathbf{1} \cdot \mathbf{3}$ & $1 \cdot 8$ & $2 \cdot 1$ \\
\hline Serine & $5 \cdot 2$ & $4 \cdot 9$ & $5 \cdot 5$ & $5 \cdot 2$ & $4 \cdot 2$ & $5 \cdot 4$ & $4 \cdot 0$ \\
\hline Threonine & $5 \cdot 8$ & $5 \cdot 4$ & $4 \cdot 2$ & $5 \cdot 4$ & 6.9 & $5 \cdot 6$ & $5 \cdot 7$ \\
\hline Proline & $5 \cdot 1$ & $5 \cdot 1$ & $7 \cdot 6$ & $3 \cdot \overline{6}$ & $4 \cdot 7$ & $7 \cdot 2$ & $4 \cdot 3$ \\
\hline Histidine & $2 \cdot 0$ & 1.5 & 0.7 & $2 \cdot 7$ & $2 \cdot 2$ & $1 \cdot 6$ & 1.9 \\
\hline Lysine Basic & $\mathbf{1 5} \cdot \mathbf{6}$ & $17 \cdot 6$ & $29 \cdot 7$ & $\mathbf{1 3} \cdot \mathbf{1}$ & $9 \cdot 0$ & $18 \cdot 8$ & $13 \cdot 1$ \\
\hline Arginine & $9 \cdot 2$ & $7 \cdot 3$ & $2 \cdot 1$ & $9 \cdot 8$ & $14 \cdot 0$ & $6 \cdot 1$ & $10 \cdot 0$ \\
\hline Lysine: arginine & $1 \cdot 7$ & $2 \cdot 4$ & $14 \cdot 1$ & $1 \cdot 3$ & $\mathbf{0 . 6}$ & $\mathbf{3} \cdot \mathbf{1}$ & $1 \cdot 3$ \\
\hline Basic: acidic & 1.9 & $2 \cdot 0$ & $3 \cdot 4$ & $1 \cdot 8$ & 1.5 & $2 \cdot 0$ & $1 \cdot 8$ \\
\hline$N$-Terminal amino acids & & & & & & & \\
\hline Alanine & 34 & 77 & 9 & 10 & 96 & 51 & 79 \\
\hline Proline & 51 & 7 & 8 & 70 & 3 & 9 & 5 \\
\hline Glycine & 6 & $\mathbf{3}$ & 34 & 3 & 0.5 & 8 & $\mathbf{5}$ \\
\hline Others & 9 & 13 & 49 & 17 & 0.5 & 32 & 11 \\
\hline $\begin{array}{l}\text { Weight (g./mole of } \\
N \text {-terminal amino acids) }\end{array}$ & 27000 & 34000 & 52000 & 28500 & 18000 & 53400 & 21700 \\
\hline
\end{tabular}

* No corrections have been made for hydrolytic losses, which would be unimportant except in the following cases, in which the figures given have been reported: serine, $20 \%$; threonine, $8 \%$; tyrosine, $8 \%$ (Crampton, Stein \& Moore, 1957).

Wheat-germ histone (200 mg.) was dissolved in $30 \mathrm{ml}$. of water. Acetone $(150 \mathrm{ml}$.) was then added, followed by $0.1 \mathrm{ml}$. of $\mathrm{N}$-hydrochloric acid. The precipitate that formed (A) was removed by centrifuging and $200 \mathrm{ml}$. of acetone added to the supernatant to precipitate the remainder of the histone (B).

Precipitate (A) was dissolved in $25 \mathrm{ml}$. of water and $125 \mathrm{ml}$. of acetone was added, followed by $0.2 \mathrm{ml}$. of concentrated hydrochloric acid. The histone was recovered by centrifuging and dissolved and reprecipitated once more in the same way. The white precipitate was washed three times with aceton $\Theta$ and dried under vacuum.

Precipitate (B) was reprecipitated twice in a similar manner but $20 \mathrm{ml}$. of water, $200 \mathrm{ml}$. of acetone and $0.2 \mathrm{ml}$. of concentrated hydrochloric acid were used.

The total and $N$-terminal amino acid analyses are given in Table 1 together with the analyses of calfthymus-histone fractions for comparison. The starch-gel-electrophoresis patterns of the fractions are given in Fig. 1.

Fractionation procedures involving precipitation with trichloroacetic acid or ethanol gave similar fractions but failed to separate any arginine-rich histones.

When an equal volume of aqueous ammonia solution (sp.gr. 0.880 ) was added to $5 \mathrm{mg}$. of wheat-germ histone in $1 \mathrm{ml}$. of water a faint cloudiness was observed, but no precipitate formed. The arginine-rich and moderately lysine-rich histones of calf thymus are precipitated under these conditions.

Amino acid and $\mathrm{N}$-terminal group analysis. These were determined as described by Phillips (1958) and Phillips \& Johns (1959) by a modification of the fluorodinitrobenzene method of Sanger (1945).

\section{DISCUSSION}

The results show that the histones extracted from wheat germ are markedly different from those extracted from the tissues of the calf and the rat. The bands that normally correspond to the argininerich fraction when calf-thymus histone is run on starch gel are hardly detectable in the wheat-germ histone. The finding that $77 \%$ of all the $N$-terminal amino acids are alanine is therefore surprising, since in all animal tissues so far examined $N$ terminal alanine is associated with the argininerich histones (Hnilica et al. 1962). In a whole histone from calf thymus from which the argininerich histones have been removed, the main $N$. terminal amino acid is proline.

There seems to be no reason to expect that the arginine-rich histone is lost during the preparation 


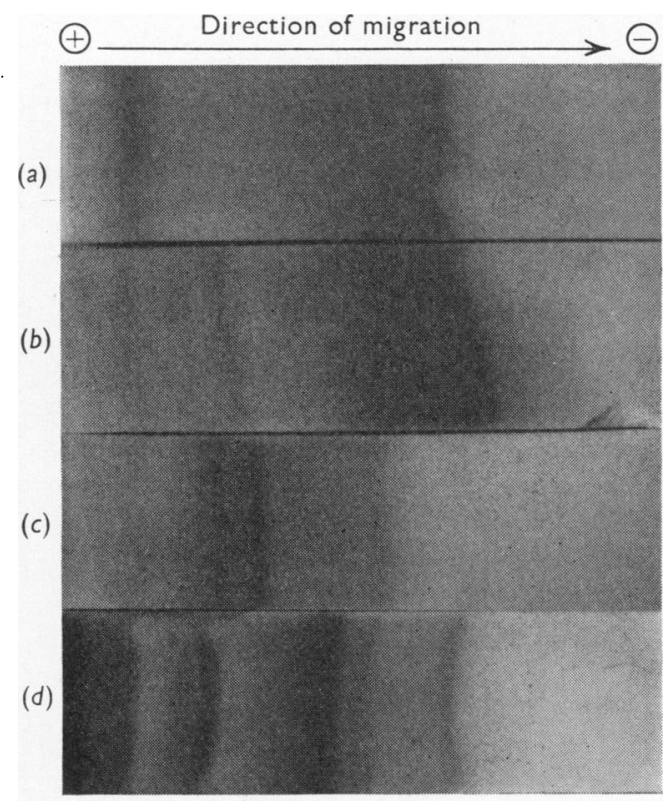

Fig. 1. Starch-gel-electrophoresis patterns, obtained under similar conditions, of the histones of calf thymus and wheat germ (in each case the origin is the edge of the photograph at the left). (a) Moderately lysine-rich fraction of wheat germ (B); (b) whole histone from wheat germ; (c) lysinerich fraction of wheat germ $(A) ;(d)$ whole histone from calf thymus.

of the deoxyribonucleoprotein or that it is not extracted with aqueous acid. In fact, Vendrely, Knobloch-Mazen \& Vendrely (1960) have shown by repeated dissociation and reassociation of deoxyribonucleoprotein prepared from fish-erythrocyte nuclei that it is the lysine-rich histones that are liable to be lost.

Cruft, Mauritzen \& Stedman (1957b) stated that the principal fraction of wheat-germ histone was unlike the main fraction obtained from animal tissues (arginine-rich fraction designated $\beta$-histone), and in fact it more closely resembled their $1.6 \mathrm{~s}$ $\gamma$-fraction from ox thymus. This is in agreement with our results, as the $1.6 \mathrm{~s} \gamma$-fraction is a slightly lysine-rich histone (Cruft, Hindley, Mauritzen \& Stedman, $1957 a$ ). Cruft et al. (1957b) also observed that the wheat-germ histone failed to aggregate on raising the $\mathrm{pH}$ of a solution above 5 , in contrast with the animal histones. This is consistent with the absence of arginine-rich histones and the nonprecipitation with aqueous ammonia solution described above.

Other facts indicating the probable absence in any quantity of arginine-rich histones, similar to those extracted from animal tissues, are the failure to extract them from the original tissue by the ethanol-hydrochloric acid extraction method of Johns et al. (1960) or to separate them from the whole-wheat-germ histone by chromatography or fractional precipitation.

The lysine-rich fraction (A) also appears to be different from the lysine-rich fraction of animal histones, in that the lysine:arginine ratio is only about 3, as compared with 6 or more for the animal fractions. The values for the acidic amino acids are also much higher (see Table 1). This histone is not extracted with $5 \%(\mathrm{w} / \mathrm{v})$ perchloric acid (Johns \& Butler, 1962), whereas all animal tissues so far examined yield a lysine-rich histone by this method. It is also precipitated first (fraction A) by the addition of acetone to an acid solution of whole histone from wheat germ, whereas in animal histones it is the most soluble group under similar conditions (Ui, 1957). It has, however, a high proline content, which is characteristic of this fraction in animal tissues.

The moderately lysine-rich fraction (B) is similar in total amino acid analysis to the moderately lysine-rich group (f2) from animal histones. However, the main $N$-terminal amino acid is alanine instead of proline. The starch-gel-electrophoresis picture is also markedly different. The whole group of slightly lysine-rich histones from calf thymus gives at least three protein bands whereas with this group from wheat germ only one slow-moving band and one main diffuse band are apparent (see Fig. 1).

\section{SUMMARY}

1. A process for the extraction of histones from wheat germ is given.

2. A partial fractionation with acetone is described and the fractions have been examined by amino acid analysis and by starch-gel electrophoresis.

3. The fraction corresponding to the argininerich histones of animal tissues appears to be missing, but a lysine-rich and a moderately lysine-rich histone have been obtained.

4. These components differ markedly from similar fractions from animal tissue; e.g. the predominant $N$-terminal group in both cases is alanine, which is the $N$-terminal of the argininerich histones of the animal tissues examined.

We wish to thank Miss P. Simson for the amino acid analyses and $\mathrm{Mr} \mathrm{D}$. Power for valuable technical assistance. We are indebted to Dr P. W. Russell Eggitt of Spillers Ltd., Cambridge, for kindly providing a quantity of wheat germ. This investigation has been supported by grants to the Chester Beatty Research Institute (Institute of Cancer Research: Royal Cancer Hospital) from the Medical Research Council, the British Empire Cancer Campaign, 
the Anna Fuller Fund and the National Cancer Institute of the National Institutes of Health, U.S. Public Health Service.

\section{REFERENCES}

Crampton, C. F., Stein, W. H. \& Moore, S. (1957). J. biol. Chem. 225, 363.

Cruft, H. J., Hindley, J., Mauritzen, C. M. \& Stedman, E. (1957a). Nature, Lond., 180, 1107.

Cruft, H. J., Mauritzen, C. M. \& Stedman, E. (1957b). Phil. Trans. B, 241, 93.

Davison, P. F., James, D. W. F., Shooter, K. V. \& Butler, J. A. V. (1954). Biochim. biophys. Acta, 15, 415.

Hnilica, L., Johns, E. W. \& Butler, J. A. V. (1962). Biochem. J. 82, 123.
Johns, E. W. \& Butler, J. A. V. (1962). Biochem. J. 82, 15. Johns, E. W., Phillips, D. M. P., Simson, P. \& Butler, J. A. V. (1960). Biochem. J. 77, 631.

Johns, E. W., Phillips, D. M. P., Simson, P. \& Butler, J. A. V. (1961). Biochem. J. 80, 189.

Mirsky, A. E. \& Pollister, A. W. (1942). Proc. nat. Acad. Sci., Wash., 28, 344.

Phillips, D. M. P. (1958). Biochem. J. 68, 35.

Phillips, D. M. P. \& Johns, E. W. (1959). Biochem. J. 72, 538.

Phillips, D. M. P. \& Simson, P. (1962). Biochem. J. 82, 236.

Sanger, F. (1945). Biochem. J. 39, 507.

Ui, N. (1957). Biochim. biophys. Acta, 25, 493.

Vendrely, R., Knobloch-Mazen, A. \& Vendrely, C. (1960). Biochem. Pharmacol. 4, 19.

\title{
A Method for the Determination of Cystine plus Cysteine in Proteins
}

\author{
By J. C. FLETCHER AND A. ROBSON \\ Wool Industries Research Association, Torridon, Headingley, Leeds 6
}

(Received 6 March 1962)

At the present time, the determination of the amino acid composition of a protein offers few difficulties. Only cysteine, cystine and tryptophan provide exceptions to this general statement. Cystine and cysteine suffer variable and often considerable destruction during acid hydrolysis, and tryptophan is almost completely destroyed. Several approaches have been adopted to circumvent this difficulty with cystine and cysteine. Schram, Moore \& Bigwood (1954) oxidized the half-cystine residues to cysteic acid residues before hydrolysing the protein. Thompson (1955) carried out the oxidation with bromine after a partial acid hydrolysis. Several workers (Kolthoff, Anastasi \& Tan, 1958; Human, 1958; Cecil \& Loening, 1960; Leach, $1960 a, b)$ sought to determine disulphide and thiol groups in intact proteins with reagents, such as monofunctional mercurials, that react specifically with thiol groups, the cystine being first reduced; this approach is important because, in addition to determining total thiol plus disulphide, it can provide information about the reactivities of individual residues. The colorimetric method of Glazer \& Smith (1961) combines partial acid hydrolysis with disulphide interchange between protein cystine and cysteine and bis(dinitrophenyl)cystine. Although for most proteins these various methods give concordant results, there are still several well-characterized proteins for which the number of half-cystine residues is not known with certainty.

The method described below had its origin in an investigation of the sulphur balance of wool keratin and, in particular, the discrepancy between the chromatographic and colorimetric estimations for the cystine content of wool hydrolysates (Corfield \& Robson, 1955). In a general attack on this problem, ${ }^{35} \mathrm{~S}$-labelled wool was obtained by oral administration of $\left[{ }^{35} \mathrm{~S}\right]$ sulphate to a sheep, and hydrolysates of this wool were examined by chromatography on starch columns (Lewis, Robson \& Tiler, 1960). The hydrolysates were found to contain, in addition to cystine and methionine, several other ${ }^{35}$ S-labelled substances, which together accounted for about $10 \%$ of the total activity. One of these substances was identified as cysteine. In an effort to find out whether these compounds were produced by the decomposition of cystine during hydrolysis, or whether they were derived from other sulphur-containing moieties in the original wool, unlabelled wool was hydrolysed in the presence of $\left.{ }^{35} \mathrm{~S}\right]$ cystine. Chromatography of the resulting hydrolysate showed that, though the distribution of ${ }^{35} \mathrm{~S}$-labelled peaks was not as complex as that given by the ${ }^{35}$ S-labelled wool hydrolysate, the major unidentified peaks were common to both chromatograms; it thus appears that the greater part of the 'missing' sulphur in wool hydrolysates is present as compounds which are derived from cystine. The formation of these compounds does not merely involve a straightforward breakdown of cystine under acid conditions, as they are not formed when $\left[{ }^{35} \mathrm{~S}\right]$ cystine alone is boiled with acid. The specific activities of the 